\title{
Late diagnosis of retinoblastoma in a developing country
}

\author{
Guillermo Chantada, Adriana Fandiño, Julio Manzitti, Luis Urrutia, Enrique Schvartzman
}

\begin{abstract}
Objectives-To assess the diagnostic process of retinoblastoma in a developing country.

Study design-Prospective survey of 95 consecutive parents of patients with retinoblastoma.

Results-Fifty six parents consulted initially with a paediatrician. Their children tended to be younger, with a significantly higher frequency of advanced disease. Only half of the patients who consulted with a paediatrician were appropriately referred to an ophthalmologist; the paediatrician underestimated the complaints in the remainder. Children taken to an ophthalmologist were older and had less advanced disease. In about three quarters of these children, a diagnosis of retinoblastoma was suspected by the ophthalmologist on the first visit. Parents of patients with more advanced disease consulted significantly later. Poor parental education correlated significantly with late consultation. Lack of health insurance and living outside Buenos Aires City correlated significantly with an increased risk of extraocular disease.

Conclusions-Paediatricians are the first health professional seen by most children with retinoblastoma. However, the diagnosis is not readily established. There is also a delay in consultation by parents, which is significantly longer in cases with advanced extraocular disease. Socioeconomic factors and access to health care might play a role in delayed diagnosis. (Arch Dis Child 1999;80:171-174)
\end{abstract}

Servicio de

Hemato-oncología, Hospital JP Garrahan, Combate de los Pozos 1881 (1245), Buenos

Aires, Argentina

G Chantada

E Schvartzman

Department of Ophthalmology, Hospital JP Garrahan A Fandiño

J Manzitti

Department of Clinical Paediatrics, Hospital JP Garrahan

L Urrutia

Correspondence to:

Dr Chantada.

email: garrahan@giga.com.ar

Accepted 14 August 1998

Retinoblastoma is the most common intraocular malignancy in children. However, it is an uncommon tumour accounting for 3\% of all childhood malignancies in developed countries. ${ }^{1}$ There is indirect evidence that it might be more frequent in some developing areas such as Latin America, Africa, and India. ${ }^{2}$ In these areas, retinoblastoma is usually the most frequent solid tumour seen in paediatric oncology units. ${ }^{2}$ In this setting, retinoblastoma is diagnosed late, usually when extraocular dissemination has occurred and the prognosis is poor. Late referral might account for the delayed diagnosis, ${ }^{3}$ but it has also been suggested that retinoblastoma might present in a different and more aggressive way at a later age in these countries. ${ }^{4}$ Nevertheless, these issues have not been investigated in depth. The aim of this study was to assess the diagnostic process of patients with retinoblastoma in Argentina and to determine the role of the general paediatrician.

\section{Material and methods}

SETTING

The Hospital de Pediatría JP Garrahan is the largest tertiary care paediatric centre in Argentina. It serves the population of Buenos Aires City and surrounding areas (population 11 million), but patients are referred from all over the country. The ophthalmology and haematooncology service admit a mean of 25 patients with retinoblastoma every year and all are enrolled on prospective treatment protocols.

DESIGN

Our study consisted of the prospective recording of the following data on 95 consecutive patients with retinoblastoma admitted from 1994 to 1997. A description of the patients' signs and symptoms, their date of onset, and an assessment of the diagnostic process were recorded. Each family was interviewed to determine if they had taken the child to a paediatrician or to an ophthalmologist after noticing the first clinical abnormality. We also recorded whether patients were readily referred or whether other consultations were necessary, and the time between the onset of symptoms and diagnosis. Socioeconomic information was obtained from all patients at diagnosis.

STAGING

The Grabowski, Abramson, and Ellsworth clinicopathological classification ${ }^{5}$ was used for staging. In brief, patients with intraocular disease are considered to be stage I, those with orbital extension are stage II, and those with metastatic disease are stage III (central nervous system (CNS) metastasis) and stage IV (haematogenous metastasis).

Ninety five consecutive patients with retinoblastoma were surveyed. Fifty four had unilateral disease. Sixty one had stage I disease, 28

Binomial test or Yates corrected $\chi^{2}$ analysis were used for analysis of proportions and the Mann-Whitney U test was used for analysis of continuous variables. Logistic regression analysis was used to assess risk factors for late consultation and extraocular disease. $p$ Values of $<0.05$ were considered significant. Statistica V5.1/97 was used for processing the data.

\section{Results}


Table 1 Initial findings in 95 patients with retinoblastoma

\begin{tabular}{|c|c|c|c|}
\hline & $\begin{array}{l}\text { Patients taken to } \\
\text { a paediatrician } \\
(n=56)\end{array}$ & $\begin{array}{l}\text { Patients taken to an } \\
\text { ophthalmologist } \\
(n=39)\end{array}$ & $p$ value \\
\hline \multicolumn{4}{|l|}{ Initial signs } \\
\hline Leukocoria & 46 & 31 & NS \\
\hline Strabismus & 25 & 12 & $0.024 \dagger$ \\
\hline Advanced symptoms* & 10 & 3 & $0.046 \dagger$ \\
\hline Unilateral/bilateral & $29 / 27$ & $25 / 14$ & NS $\dagger$ \\
\hline Median (range) age (months) & $15(1-83)$ & $23(0-104)$ & NS (0.07) \\
\hline Stage I & 31 & 30 & $1 v 2+3<0.05 \ddagger$ \\
\hline Stage II & 22 & 6 & \\
\hline Stage III/IV & 3 & 3 & \\
\hline Health insurance & 23 & 16 & NS $\ddagger$ \\
\hline \multicolumn{4}{|l|}{ Educational status } \\
\hline Illiterate/elementary & 37 & 25 & NS $\ddagger$ \\
\hline High school/college & 19 & 14 & \\
\hline \multicolumn{4}{|l|}{ Place of residency } \\
\hline Urban & 47 & 35 & NS \\
\hline Rural & 9 & 4 & \\
\hline Buenos Aires area & 29 & 23 & \\
\hline Rest of the country & 27 & 16 & \\
\hline \multicolumn{4}{|l|}{ Median time (range) to initial } \\
\hline consultation (weeks) & $15(1-90)$ & $15(1-100)$ & NS \\
\hline
\end{tabular}

^Buphthalmos, orbital swelling, etc; †Binomial test; $\ddagger$ Yates corrected $\chi^{2}$ analysis.

Table 2 Interval from symptom onset to consultation (early diagnosis group $<24$ weeks and late diagnosis group $\geqslant 24$ weeks)

\begin{tabular}{|c|c|c|c|}
\hline Variable & $\begin{array}{l}\text { Early diagnosis group } \\
(n=75)\end{array}$ & $\begin{array}{l}\text { Late diagnosis group } \\
(n=20)\end{array}$ & $p$ value \\
\hline Stage I & 53 & 8 & $<0.005$ \\
\hline Stage II & 20 & 8 & \\
\hline Stage III/IV & 2 & 4 & \\
\hline Doctor & & & NS \\
\hline Paediatrician & 45 & 11 & \\
\hline Ophthalmologist & 30 & 9 & \\
\hline Health insurance & & & NS \\
\hline Yes & 35 & 4 & \\
\hline No & 40 & 16 & \\
\hline Parental education & & & $<0.018$ \\
\hline Elementary or lower & 44 & 18 & \\
\hline High school or higher & 31 & 2 & \\
\hline Place of residency & & & NS \\
\hline Urban & 66 & 16 & \\
\hline Rural & 9 & 4 & \\
\hline Buenos Aires area & 41 & 11 & \\
\hline Rest of the country & 34 & 9 & \\
\hline
\end{tabular}

had stage II, and six had stage III/IV disease. There was a family history of retinoblastoma in eight cases.

Thirty nine families had at least one member with a stable job as well as health insurance. Fifty six families lacked any health insurance and a stable job and their actual income was below standard. Eighty two families lived in urban areas and 13 in rural zones of Argentina. Fifty two lived in the Buenos Aires area and 43 lived in other provinces of Argentina. In 59 families, at least one member had completed elementary school, 23 had completed high school, and in 10 families at least one member had a college education. In three families both parents were illiterate.

Fifty six patients were taken initially to a paediatrician and 39 to an ophthalmologist. A positive family history for retinoblastoma was elicited in three patients taken to a paediatrician, and in five patients taken to an ophthalmologist (table 1).

Of the 56 patients who consulted with a paediatrician, only 30 were readily referred to an ophthalmologist and in the remaining 26 cases, the paediatrician underestimated the complaint and the family sought further consultations with another paediatrician $(n=9)$ or an ophthalmologist $(n=17)$. Of the 39 patients who consulted initially with an ophthalmologist, the diagnosis was made promptly in 30, whereas in the remaining nine the complaints were underestimated and the diagnosis was made after a further consult with another ophthalmologist.

Patients with greater disease extension consulted significantly later. Patients with intraocular disease had a median time between the detection of signs and consultation (lag time) of 12 weeks (range, 1-80), those with orbital extension 24 weeks (range, 1-90), and those with metastatic disease 50 weeks (range, 1-100). These differences were significant $(\mathrm{p}<0.05)$. Patients were classified arbitrarily according to the interval between the onset of symptoms and consultation into the following groups:

(1) early consultation ( $<24$ weeks; $\mathrm{n}=75$ )

(2) late consultation ( $\geqslant 24$ weeks; $n=20$ ).

Extraocular disease (stages II, III, and IV) was significantly more common in the late consultation group by univariate analysis. (Early consultation: intraocular (stage I) 53 patients $v$ extraocular 22 patients; late consultation: intraocular (stage 1) eight patients $v$ extraocular 12 patients; $\mathrm{p}<0.02$.) Parental education correlated significantly to late consultation both by univariate and multivariate analysis $(\mathrm{p}<0.001)$. Only parental education was significantly associated with late consultation on multivariate analysis: adjusted odds ratio for patients with elementary education or less was 6.34 (95\% confidence interval (CI), 37 to $29.3 ; \beta$ coefficient (SE), 1.847 (0.781); $\mathrm{p}<0.0181$ ) (table 2).

Lack of health insurance, living in a city other than Buenos Aires, parental education, and ini-

Table 3 Risk factors for extraocular (stage II or greater) disease

\begin{tabular}{|c|c|c|c|c|c|c|}
\hline Variable & Intraocular & Extraocular & $p$ value ${ }^{*}$ & $\beta$ coefficient (SE) & $\begin{array}{l}\text { Adjusted odds ratio } \\
(95 \% \mathrm{CI})\end{array}$ & $p$ valuet \\
\hline \multicolumn{7}{|l|}{ Doctor } \\
\hline Paediatrician & 31 & 25 & NS & $1.372(0.552)$ & $3.94(1.32-11.8)$ & $<0.01$ \\
\hline Ophthalmologist & 30 & 9 & & & & \\
\hline \multicolumn{7}{|l|}{ Health insurance } \\
\hline Yes & 33 & 6 & $<0.001$ & $-1.792(0.575)$ & $6.00(1.94-18.5)$ & NS \\
\hline No & 28 & 28 & & & & \\
\hline \multicolumn{7}{|l|}{ Place of residency } \\
\hline Urban & 54 & 28 & NS & $0.438(0.830)$ & $1.55(0.3-8.06)$ & NS \\
\hline Rural & 7 & 6 & NS & $-1.411(0.566)$ & $4.1(1.35-12.4)$ & $<0.01$ \\
\hline Buenos Aires area & 38 & 14 & & & & \\
\hline Rest of the country & 23 & 20 & & & & \\
\hline \multicolumn{7}{|l|}{ Parental education } \\
\hline Elementary or lower & 33 & 29 & $<0.005$ & $1.014(0.070)$ & $2.75(0.67-11.2)$ & NS \\
\hline High school or higher & 28 & 5 & & & & \\
\hline
\end{tabular}

^Binomial test and Yates corrected $\chi^{2}$ analysis; †logistic regression analysis. 
tial consultation with a paediatrician were significantly associated with extraocular disease by univariate and multivariate analysis (table 3 ).

\section{Discussion}

Extraocular dissemination of retinoblastoma (stages II, III, and IV) occurs more frequently in developing areas, leading to poorer prognosis of patients with retinoblastoma in this setting. ${ }^{2-6}$ Erwenne and Franco from Brazil showed that late referral (more than six months) correlated with extraocular extension and poor prognosis. ${ }^{3}$ Most studies failed to find a correlation between longer lag time and greater disease extension for other paediatric solid tumours. ${ }^{7-8}$ It has been suggested that patients with disseminated disease should have shorter lag time, implying that tumour biology might play an important role. ${ }^{7}$ On the other hand, based on a large cohort of patients with a single tumour, our results show that the longer the interval between the onset of symptoms and consultation, the greater the risk of disseminated disease. This finding suggests that if this lag time is shortened, there might be a concomitant decrease in the number of extraocular cases and ultimately better prognosis. However, the diagnostic process of childhood cancer is complex and many other variables might play an important role.

Late diagnosis can be caused by several factors in Argentina. Late consultation was an important factor in our study. Parents consulted at a median of 15 weeks after noticing the first symptom. Patients with extraocular disease had significantly longer periods between the onset of symptoms and the first consultation. Parental education was associated significantly with late consultation. It is likely that parents with a poorer educational background have limited information regarding signs and symptoms of retinoblastoma. Parents often stated that even though they noted an abnormality in the eye, often leukocoria, they did not relate this to the possibility of having cancer. An information programme directed at the public in general might eventually reduce lag time and indirectly reduce the number of extraocular cases. Nevertheless, our results need to be taken with caution because, even though the parents were surveyed prospectively at diagnosis, results rely only on parental reports.

Regional variations and accessibility to health care play a role in delayed diagnosis of children with solid tumours. ${ }^{7}$ The significantly increased risk for extraocular disease in children from families without health insurance services and those living outside the Buenos Aires area might reflect limited accessibility to health care services in our population.

A second cause of delay was the failure of both paediatricians and ophthalmologists to detect early signs of retinoblastoma. In our setting, paediatricians undertake paediatric general practice (primary care). In Argentina, primary paediatric care is almost universal and free of charge. Our study shows that most parents consult initially with a primary paediatrician, even in some cases where there is a family history of retinoblastoma. There was also a trend to take younger children to a paediatrician first rather than to an ophthalmologist. However, many paediatricians seem to be poorly informed about retinoblastoma. In a previous study from our group, 41 clinical paediatric residents at our centre were questioned about their knowledge of retinoblastoma. ${ }^{9}$ Even though most identified leukocoria as the most frequent sign, only one quarter stated that strabismus could be a presenting sign. Strabismus is more frequent in younger patients with macular involvement. ${ }^{1}$ In addition, only one fifth of the residents surveyed identified bilateral retinoblastoma as a disease occurring in children younger than 2 years. The remainder thought that this tumour occurs at an older age. ${ }^{9}$ These two findings are particulary concerning because, in our study, younger children were more likely to be taken initially to a paediatrician. An educational programme during the residency period might be warranted.

Our results also suggest that most patients with advanced disease were taken to a paediatrician significantly more often. This might be explained by the fact that these children often present with orbital swelling resembling cellulitis, irritability caused by glaucoma, or a red painful eye; these symptoms are more likely to impair the child's general condition, leading to a consultation with a general paediatrician first.

The general paediatrician has a low index of suspicion for cancer. ${ }^{10}$ Cancer may present in children with non-specific findings in slowly progressing malignancies, such as brain tumours, and late diagnosis is common. ${ }^{11}$ The availability of newer imaging technology has not changed the delay in diagnosis. ${ }^{11}$ Alternatively, cancer may present with specific signs and symptoms, such as visible or palpable tumours. Retinoblastoma usually presents with leukocoria, and this is a specific sign with a small differential diagnosis. ${ }^{1}$

Patients who consulted initially with an ophthalmologist were also diagnosed late. It was disturbing to find that in about a quarter of cases, ophthalmologists failed to diagnose retinoblastoma. In these cases, ocular fundoscopy under anaesthesia was not done.

\section{CONCLUSIONS}

Retinoblastoma is diagnosed late in Argentina and this might account for the relatively high frequency of extraocular disease. Both late consultation by parents, especially those with a poor educational background, and a lack of awareness by paediatricians and ophthalmologists contributed to this delay. Poor accessibility to health care might also play a role in delay.

We are indebted to Dr F Sackmann-Muriel for his critical review of the manuscript.

1 Donaldson S, Egbert P, Newsham I, Cavenee W. Retinoblastoma. In: Pizzo P, Poplack D, eds. Principles and practice of pediatric oncology, 3rd ed. Philadelphia: PA Lippincott, 1997:669-715.

2 Magrath I, Shad A, Epelman S, et al. Pediatric oncology in countries with limited resources. In: Pizzo P, Poplack D, eds. Principles and practice of pediatric oncology, 3rd ed. eds. Principles and practice of pediatric oncology

3 Erwenne C, Franco E. Age and lateness of referral as determinants of extraocular retinoblastoma. Ophthalmic Pediatrics and Genetics 1989;10:179-84. 
4 Schultz K. Why look at retinoblastoma in developing countries as a potentially unique disease [abstract]? Med Pediatr

5 Grabowski EF, Abramson DH. Intraocular and extraocular retinoblastoma. Hematol Oncol Clin North Am 1987;1:72135

6 Schvartzman E, Chantada G, Fandiño A, Davila M, Raslawski E, Manzitti J. Results of a stage-based protocol for the treatment of retinoblastoma. F Clin Oncol 1996;14: 1532-6.

7 Saha V, Love S, Eden T, Micallef-Eynaud P, Mac Kinlay G. Arch Dis Child 1993;68:771-4.
8 Pollock B, Kirsher J, Vietti T. Interval between symptom onset and diagnosis of pediatric solid tumors. $\mathcal{F}$ Pediatr 1991;119:725-32.

9 Chantada G, Fandiño A, Urrutia L, Nasanoski J, Manzitti J, Schvartzman E. Papel del pediatra en el proceso diagnóstico del retinoblastoma. Medicina Infantil (Buenos Aires) 1997;IV:251-5.

10 Steuber CP, Nesbit ME. Clinical assessment and differential diagnosis of the child with suspected cancer. In: Pizzo P, Poplack D, eds. Principles and practice of pediatric oncology, 3rd ed. Philadelphia: PA Lippincott, 1997:129-39.

11 Edgenworth J, Bullock P, Bailey A, et al. Why are brain tumors still being missed? Arch Dis Child 1996;74:148-51.

\section{The fairy godmother effect}

Go on, admit it-you don't believe in fairy godmothers, do you? They only exist in Disney films, don't they? Well the remarkable results of recent US research might help to change things, but for "fairy godmother" substitute home nurse or health visitor. A study that began over 20 years ago (Davis Olds and colleagues. Fournal of the American Medical Association 1998;280:1238-44) has shown that home visiting by nurses during pregnancy and the child's first two years can reduce antisocial behaviour at adolescence in the children of disadvantaged families. Four hundred pregnant women with no previous livebirths were enrolled in 1978-80 and 315 of the children of these pregnancies were studied at age 15 years. Most ( $85 \%$ ) were young, unmarried, or from low socioeconomic status (SES) households. The pregnant mothers were randomly assigned to four groups: group 1-sensory and developmental screening at 12 and 24 months with appropriate action; group 2-as group 1 but free transport to antenatal and well child clinics; group 3-as group 2 but nurse home visits during pregnancy; group 4-as group 3 but home visits continued until the child was 2 years old. The mean number of visits was 9 during pregnancy and 23 during the child's first 2 years, and the nurses concentrated on three aims: to promote healthy behaviour during pregnancy and the child's first 2 years, to promote good child care, and to help the mothers' personal development in such aspects as family planning, education, and work.

Of the 315 adolescents, $90 \%$ were born to white mothers, $60 \%$ to unmarried mothers, $60 \%$ to low SES mothers, and $50 \%$ to mothers under 19. The adolescent children of unmarried, low SES mothers in group 4 (prenatal and postnatal visits) reported significantly fewer problems than did those in the other groups. These problems included running away, arrest, convictions, probation violations, multiple sex partners, smoking cigarettes, and consuming alcohol. The children of mothers in group 3 (antenatal nurse home visiting only) did better than those of mothers in groups 1 and 2 but not as well as those of group 4 mothers.

Although it has a certain "too good to be true" ring to it (it seems almost incredible that monthly visits can counter so much disadvantage and social exclusion) this work is in some respects in accord with studies of child rearing in non-human primates. The exact mechanism of the effect seems unclear but it is suggested that the nursing input reduces health risks to the fetus (by reducing tobacco and alcohol consumption, for instance) and improves the mothers' education and emotional well being during child rearing. This may alter a developmental pathway that begins in early life and leads to antisocial behaviour. (Antisocial behaviour beginning in early childhood tends to be much worse than that beginning in adolescence.) The US Department of Justice is supporting efforts to extend the programme, concentrating on deprived communities with high rates of crime.

ARCHIVIST 